\title{
Endotracheal Tubes Cleaned With a Novel Mechanism for Secretion Removal: A Randomized Controlled Clinical Study
}

\author{
Riccardo Pinciroli MD, Cristina Mietto MD, Annop Piriyapatsom MD, Christopher T Chenelle, \\ John G Thomas PhD, Massimiliano Pirrone MD, Lynn Bry MD PhD, \\ Gregory R Wojtkiewicz MSc, Matthias P Nahrendorf MD PhD, \\ Robert M Kacmarek PhD RRT FAARC, and Lorenzo Berra MD
}

\begin{abstract}
INTRODUCTION: Intubation compromises mucus clearance, allowing secretions to accumulate inside the endotracheal tube (ETT). The purpose of this trial was to evaluate a novel device for ETT cleaning. We hypothesized that its routine use would reduce tube occlusion due to mucus accumulation, while decreasing airway bacterial colonization. METHODS: Subjects were randomized to either the use of the device every $8 \mathrm{~h}$, or the institutional standard of care (blind tracheal suction) only. ETTs were collected at extubation and analyzed with high-resolution computed tomography (HRCT) for quantification of mucus volume. Microbiological testing was performed on biofilm samples. Vital signs and ventilatory settings were collected at the bedside. In-hospital follow-up was conducted, and a final evaluation survey was completed by respiratory therapists. RESULTS: Seventy-four subjects expected to remain intubated for longer than $48 \mathrm{~h}$ were enrolled (77 ETTs, 37 treatment vs 40 controls). Treated tubes showed reduced mucus accumulation $(0.56 \pm 0.12$ vs $0.71 \pm 0.28 \mathrm{~mL} ; P=.004)$ and reduced occlusion $(6.3 \pm 1.7$ vs $8.9 \pm 7.6 \% ; P=.039)$. The HRCT slice showing the narrowest lumen within each ETT exhibited less occlusion in cleaned tubes $(10.6 \pm 8.0$ vs $17.7 \pm 13.4 \%, 95 \%$ CI: $2-12.1 ; P=.007)$. Data on microbial colonization showed a trend in the treatment group toward a reduced ETT-based biomass of bacteria known to cause ventilator-associated pneumonia. No adverse events were reported. The staff was satisfied by the overall safety and feasibility of the device. CONCLUSION: The endOclear is a safe and effective device. It prevents luminal occlusion, thereby better preserving ETT nominal function. Key words: intubation; ventilation; biofilms; VAP (ventilator-associated pneumonia); airway obstruction. [Respir Care 2016;61(11):1431-1439. ( 2016 Daedalus Enterprises]
\end{abstract}

\section{Introduction}

The endotracheal tube (ETT) is a life-saving device for respiratory support and airway protection of critically ill

\footnotetext{
Drs Pinciroli, Mietto, Piriyapatsom, Pirrone, Kacmarek, and Berra are affiliated with the Department of Anesthesia, Critical Care and Pain Medicine, Massachusetts General Hospital, Boston, Massachusetts; Mr Chenelle and Dr Kacmarek are affiliated with the Department of Respiratory Care, Massachusetts General Hospital, Boston, Massachusetts; Dr Thomas is affiliated with the School of Dentistry, West Virginia University, Morgantown, West Virginia; Dr Bry is affiliated with the Center for Clinical and Translational Metagenomics, Department of Pathology, Brigham \& Women's Hospital, Boston, Massachusetts; Drs Nahrendorf and Wojtkiewicz are affiliated with the Center for System Biology, Massachusetts General Hospital, Boston, Massachusetts.
}

patients. However, its sustained presence in the trachea can have harmful consequences by disrupting the physiological mechanisms that maintain mucus homeostasis. ${ }^{1,2}$

Our group recently studied ETTs collected after discontinuation of mechanical ventilation and showed a significant degree of luminal occlusion, measured by high-resolution computed tomography (HRCT). Similar levels of

\footnotetext{
Dr Mietto presented a version of this paper at the 43rd Critical Care Congress of the Society of Critical Care Medicine 2014, held January 9-13, 2015, in San Francisco, California.

Supplementary material related to this paper is available at http:// www.rcjournal.com.
} 
ETT obstruction were also found in chest CT scans of intubated patients, despite optimal humidification and standard ETT suctioning. The degree of ETT occlusion positively correlated with in vitro measurements of air flow resistance. ${ }^{3}$ This process of mucus buildup and luminal narrowing leads to an increased ventilatory effort and might delay liberation from the ventilator. ${ }^{4,5}$ In addition, potential lung pathogens often colonize the ETT lumen. ${ }^{6,7} \mathrm{Bac}-$ teria grow as complex biofilms, ${ }^{8}$ with the plastic surface offering the ideal environment for their proliferation and acquisition of antibiotic resistance. ${ }^{9}$

\section{See the Related Editorial on Page 1560}

Nevertheless, in everyday practice, the extent of ETT biofilm formation and the degree of occlusion are generally not investigated. Despite being poorly effective, blind tracheal suctioning is a standard procedure, commonly used to clear secretions. ${ }^{10,11}$

Different novel medical devices dedicated to ETT cleaning have recently been developed. ${ }^{12}$ Among them, we published the successful use of the endOclear ${ }^{\circledR}$ (Endoclear, LLC, Petoskey, Michigan), which we reported to be an effective tool in relieving life-threatening ETT obstruction. ${ }^{13}$

We hypothesized that the effective removal of secretions would preserve ETT functionality and reduce bacterial lung colonization by preventing luminal occlusion and biofilm formation. We tested this hypothesis in a randomized, controlled clinical trial to assess the efficacy of adding ETT cleaning with the endOclear device to standard ETT maintenance in subjects expected to stay intubated for more than 48 hours. The primary aim of our study was to determine whether tubes treated with the endOclear device (cleaning group) showed an increased luminal patency compared with those receiving only the institutional standard of care (control group). Our secondary aims included: (1) biofilm reduction, (2) improved respiratory mechanics, and (3) safety and feasibility in the use of the device.

\footnotetext{
This study was funded in part by the Department of Anesthesia, Critical Care and Pain Medicine, Department of Respiratory Care, Massachusetts General Hospital. Endoclear, LLC supported microbiological testing, HRCT analysis, and supplied the endOclear devices free of charge. Microbiological testing at the Center for Clinical and Translational Metagenomics was partially funded by NIDKK P30DK034854. Dr Kacmarek is a consultant for Covidien, has received honararium ( 1 per y) for a lecture by Maquet and has received a grant from Venner Medical. None of the other authors has any conflict of interest to disclose.
}

Correspondence: Lorenzo Berra MD, Department of Anesthesia, Critical Care and Pain Medicine, Massachusetts General Hospital. White 434-B, 55 Fruit Street, Boston, Massachusetts 02114. E-mail: lberra@mgh.harvard.edu.

DOI: $10.4187 /$ respcare.04363

\section{QUICK LOOK}

\section{Current knowledge}

Endotracheal tubes (ETTs) of mechanically ventilated patients may show a significant degree of luminal occlusion due to mucus buildup. Standard tracheal suctioning does not effectively clear secretions, potentially leading to increased air flow resistance and ETT colonization.

\section{What this paper contributes to our knowledge}

The implementation of a routine ETT cleaning protocol including the use of the endOclear safely and effectively reduced ETT luminal narrowing.

\section{Methods}

\section{Study Setting and Design}

The study was conducted across 5 adult intensive care units (ICUs) at the Massachusetts General Hospital (Boston, USA). From March to September 2013, subjects 18 years of age or older were screened twice daily through electronic medical records. Subjects expected to remain on the ventilator for more than 48 hours were enrolled after signed informed consent was obtained from the subject or surrogate. Consented subjects were then randomized through sealed envelopes with a concealed 1:1 allocation to either the treatment or control group. The treatment group consisted of an ETT cleaning protocol involving tracheal suctioning immediately followed by a single pass of the endOclear device, repeated 3 times daily every 8 hours. Subjects in the control group only received the institutional standard of care, which includes blind tracheal suctioning through a closed system (Kimvent, Kimberly Clark, Roswell, Georgia) 3 times a day every 8 hours and as needed. No intervention was planned for control subjects, for whom the study was limited to data collection. The protocol ended at extubation, tracheostomy, or death. Consented subjects requiring re-intubation, reentered the protocol in the same random group to which they had originally been allocated. Members of the clinical staff and the researchers who supplied the devices and collected data at the bedside were necessarily not blinded to group allocation. However, at extubation, every ETT was assigned an unidentifiable sequential code. Data on ex vivo samples were therefore collected by blinded assessors, particularly GRW and MN for HRCT and LB for microbiology. The study was approved by the Partners HealthCare Institutional Review Board and registered on clinicaltrials.gov (NCT\#01765530). 


\section{Data Collection}

Age, sex, weight, major comorbidities, Simplified Acute Physiology Score (SAPS) II, Acute Physiology and Chronic Health Evaluation (APACHE) II, primary reasons for hospital admission and intubation were recorded at the time of randomization. During the course of enrollment, vital signs and ventilatory settings were recorded at the bedside every 8 hours. For subjects in the treatment group, data were collected twice: before and after the cleaning maneuver. Intubated subjects were connected to either a Puritan Bennet 840 (Covidien, Mansfield, Massachusetts) or Evita 4 (Dräger Medical, Lübeck, Germany) mechanical ventilator with adult size heated-wire ventilator circuits (Hudson RCI-Teleflex, Limerick, Pennsylvania) and active humidification (Neptune, Hudson RCI-Teleflex) at a $37^{\circ} \mathrm{C}$ set airway temperature, as per institutional practice. At the end of enrollment, electronic medical records were accessed for each patient to establish the incidence of ventilator-associated pneumonia (VAP), as classically defined by clinical, radiological, and laboratory findings. ${ }^{14}$ In-hospital follow-up was conducted until discharge or death.

\section{The EndOclear Device}

The endOclear is a sterile, single-use device consisting of a proximal handle, and a thin flexible catheter with a cleaning apparatus at its terminal end (Fig. 1). A distal rounded-tip mesh structure can be mechanically activated to move from a collapsed to a radially expanded position. During use, the catheter is first inserted into the ETT. Once in position, the device is activated to form a discshaped wiper that gently presses upon the ETT inner wall. The endOclear is then withdrawn from the tube over a period of 3-5 seconds, scraping secretions off the inner ETT wall. For safety purposes, the device is equipped with graduated markings and an adjustable safety guide to help prevent over insertion. A safety lock at the handle level averts untimed triggering of the device. Along with the device, a Y-shaped connector is supplied by the manufacturer. This connector allows mechanical ventilation to be continued during the maneuver and secretions to be collected in a disposable, dedicated adapter. The endOclear device is marketed as a Class 1 FDA 510(k) exempt device.

\section{Endotracheal Tube Processing}

ETTs were collected at the bedside immediately after extubation, sealed, and rapidly processed for further analysis (see the supplementary materials at http://www. rcjournal.com for a schematic overview of the ETT processing protocol from the moment of patient's extubation). Every effort was undertaken to reduce as much as possible the time

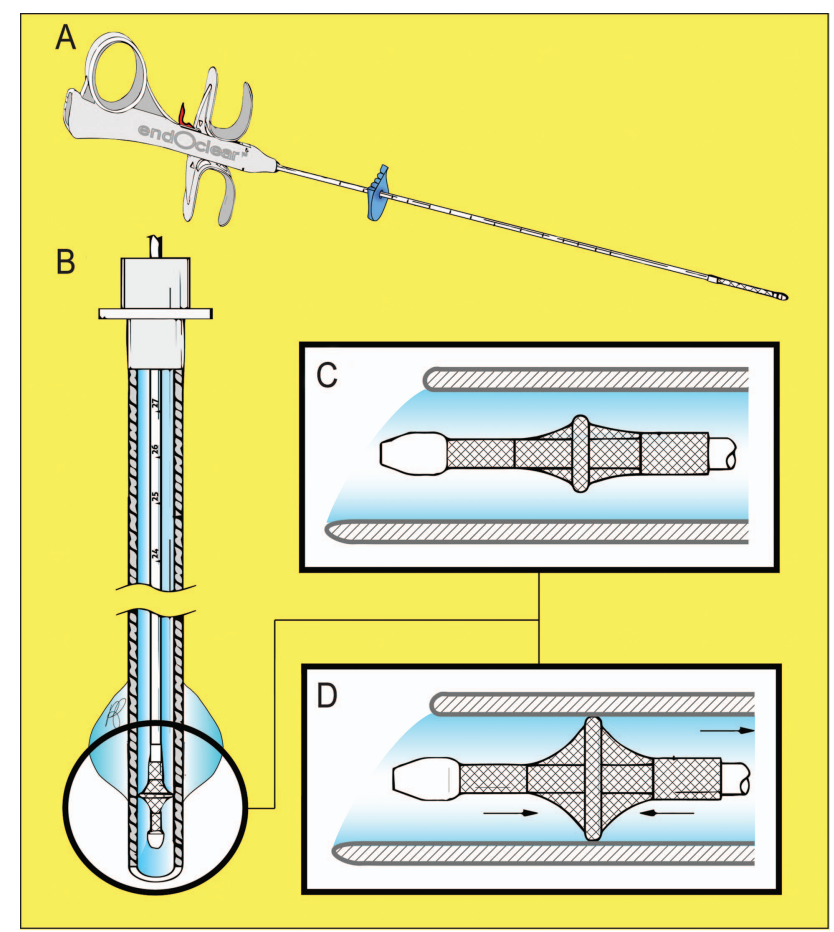

Fig. 1. A schematic representation of the endOclear device. A: A full view of the device, from the handle, to the central tube (45.7 $\mathrm{cm}$, size $3.2 \mathrm{~mm}$ ), to the cleaning apparatus. Note the red safety toggle and the blue stop, which can be positioned on the appropriate centimeter marking to avoid over-insertion. B: Insertion of the endOclear into an endotracheal tube. Detailed view of device activation from the collapsed (C) to radially-expanded configuration (D). The wiper disc diameter expands from $4.5 \mathrm{~mm}$ to approximately $9.4 \mathrm{~mm}$ once deployed. Secretions are cleared from the endotracheal tube lumen by withdrawing the expanded device.

needed to complete every step. Specifically, we aimed at limiting possible alterations of the endoluminal content occurring after extubation, to avoid imaging artifacts and bacterial contamination. A detailed report of the time lapses between the different steps of our protocol is provided in the supplementary materials at http://www.rcjournal.com.

\section{High-Resolution Computed Tomography Scanning}

HRCT was obtained for the terminal $22 \mathrm{~cm}$ end of each ETT, as already described elsewhere. ${ }^{3}$ Raw imaging data of mucus and air volumes $(\mathrm{mL})$ were acquired and subsequently converted to volume percentages (mucus/[mucus+air], $\% \mathrm{~mL}$ ). We, therefore, report as "overall occlusion" the average ratio of mucus versus total ETT inner volume (mucus + air) throughout the whole $22 \mathrm{~cm}$ tube portion. HRCT data were then analyzed slice-by-slice, to identify the single point of maximum volume occlusion within each ETT, which we refer to as "maximum occlusion" $(\% \mathrm{~mL})$. Once the slice showing the highest occlusion was identified, further computation of imaging data was per- 

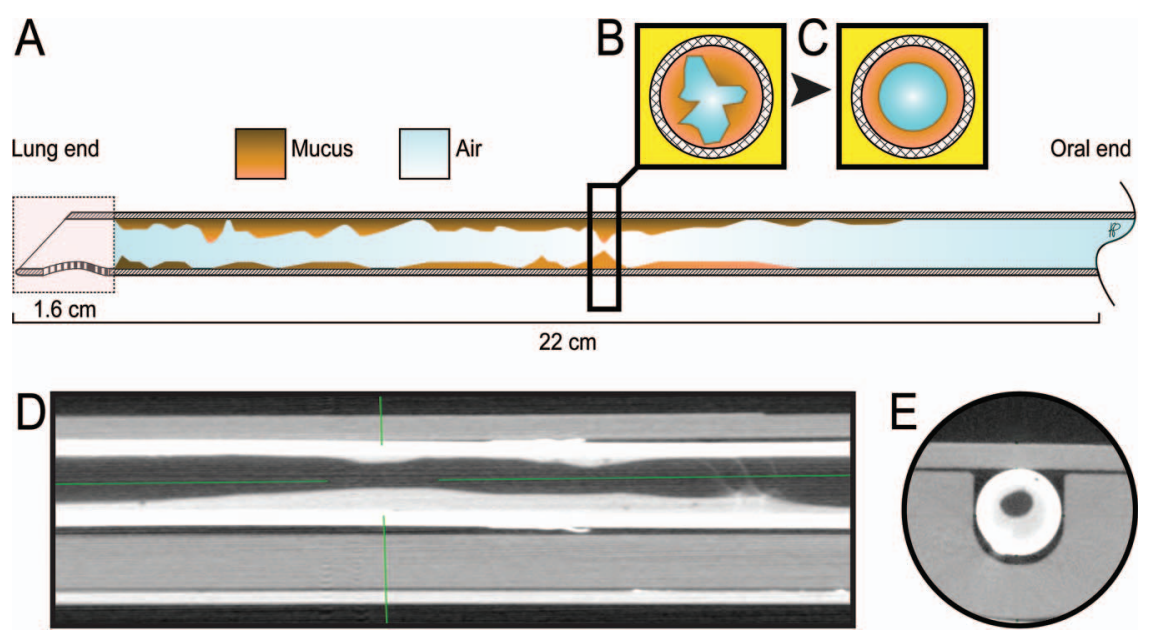

Fig. 2. A: High-resolution computed tomography (HRCT) spatial analysis. The endotracheal tube was first analyzed as a whole to collect data about the total mucus volume $(\mathrm{mL})$, and the overall occlusion \% (total mucus/(mucus + air)). The single slice showing the highest degree of luminal narrowing was also identified and studied to detect the maximum occlusion \% (B). Assuming uniform mucus distribution, its measured cross-sectional area $\left(\mathrm{CSA} ; \mathrm{cm}^{2}\right)$ was then approximated to that of a circle $(\mathrm{C})$, in order to estimate the endotracheal tube lumen actually available to airflow (minimum internal diameter, $\mathrm{mm}=\sqrt{\mathrm{CSA} \times 4 / \pi}$ ). The Murphy-eye and the beveled edge of the tip of the endotracheal tube (terminal $16 \mathrm{~mm}$ ) were excluded from HRCT analysis due to the incompletely circular cross-section, causing artifacts in the volumetric computation. Sample representative HRCT mid-sagittal (D) and transversal (E) endotracheal tube scans are also shown. CSA $=$ cross-sectional area.

formed to calculate the lowest cross-sectional area $\left(\mathrm{CSA}, \mathrm{mm}^{2}\right)$ available to air flow throughout the ETT. Approximating such CSA to that of a circle, the lowest "mucus-free" internal diameter (ID, mm) was estimated for each tube in the 2 groups. We refer to this last parameter as minimum ID. Graphical schematization of our HRCT spatial analysis is provided in Figure 2.

\section{Microbiology}

Collection of mucus samples and ETT standard microbiological testing were performed as previously described. ${ }^{3}$ Routine identification and quantitation of bacterial and fungal isolates were obtained from each collected ETT. Resistance to major antibiotics was also tested. The impact of cleaning on ETT bacterial biofilm was analyzed by grouping isolates into 4 major categories (No Growth, Pathogens, VAP-causative Gram Negatives, ${ }^{15}$ and Multi-Drug-Resistant ${ }^{16}$ ).

\section{Safety and Staff Feedback}

At the end of the trial, a standardized questionnaire was administered to registered respiratory therapists (RRTs) to collect their feedback on the use of the endOclear. Users were asked to grade the device on a scale from 1 (poor) to 4 (excellent), regarding its efficacy in cleaning the ETT, its safety, and its usability. An overall evaluation was finally requested on a scale from 1 to 10 . Respiratory therapists were instructed to promptly notify the research staff in case of any adverse event, defined as an untoward, accidental, and unfavorable circumstance temporarily associated with the cleaning maneuver and to that at least partially attributable, with or without harm being caused to the patient (eg, device malfunction or breakage, accidental extubation, tracheal injury).

\section{Statistical Analysis}

The primary end point of the study was the difference in overall ETT occlusion between the 2 groups. We hypothesized an average $2 \pm 1 \mathrm{~mL}$ less mucus, as an effect of the cleaning device in the treatment arm. Based on preliminary HRCT data, we anticipated enrolling a total of 74 subjects in a randomized-controlled design (37 subjects per group) to detect this difference for a statistical power of $80 \%$, with a 2-sided significance level of 0.05 in a 2 -sample $t$ test. Further details about the conducted power analysis are provided in the supplementary materials at http://www.rcjournal.com.

Normal distribution of each tested variable was assessed with the Shapiro-Wilk test. Data are reported as mean \pm standard deviation (SD) or median [interquartile range, IQR], as appropriate. Differences between the 2 groups were tested with the Student $t$ test or Wilcoxon rank-sum test based on distribution normality. Ratios and proportions between groups were compared using the chi-square test. A $P<.05$ was considered statistically significant.

The analysis was conducted with Stata 12.0 (Stata Corporation, College Station, Texas) and Prism 6 (GraphPad, La Jolla, California) software. 


\section{ETT SECRETION REMOVAL}

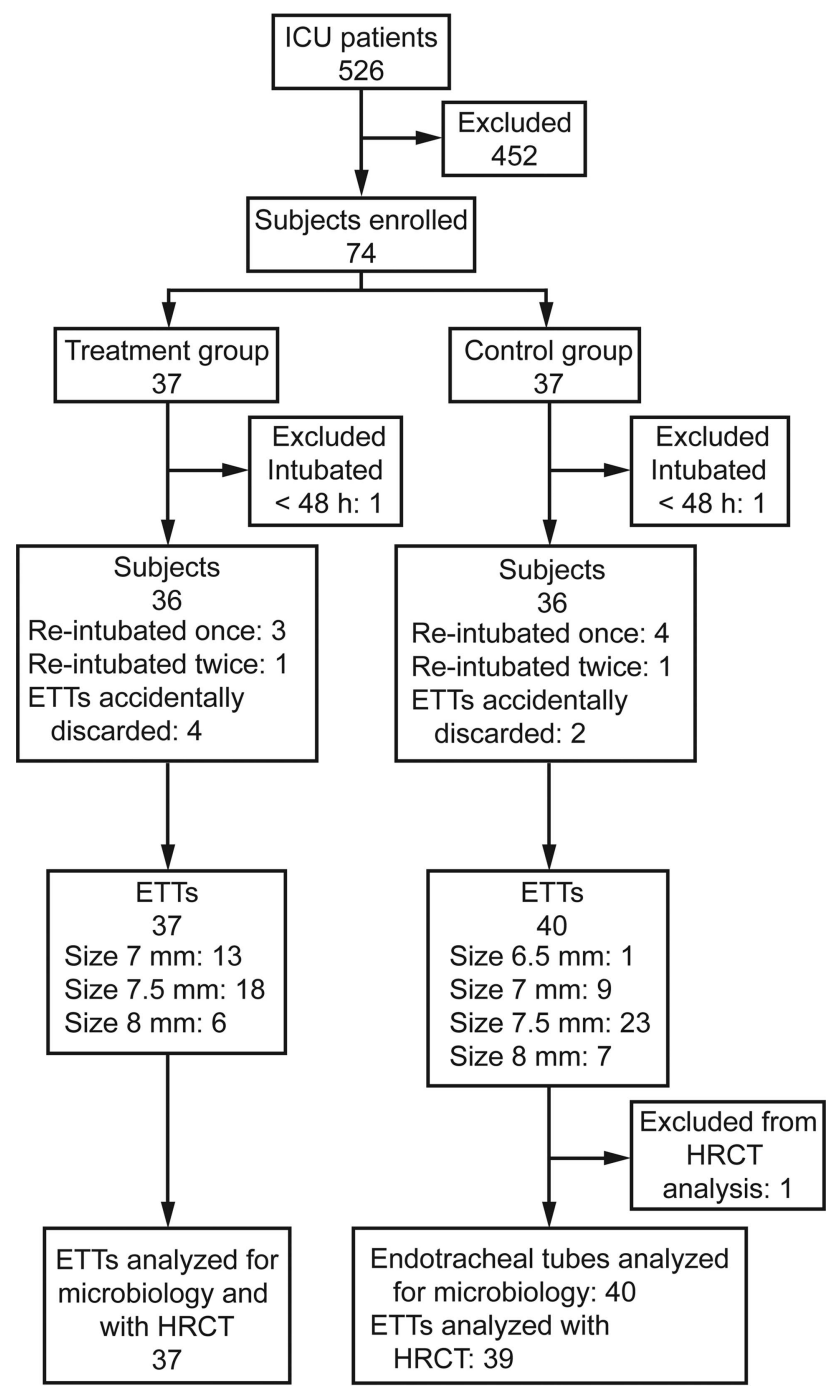

Fig. 3. Flow chart. ETT = endotracheal tube, HRCT = high-resolution computed tomography.

\section{Results}

A total of 526 intubated subjects were screened to enroll 74 subjects, subsequently randomized 37 versus 37 to the treatment and control groups. One subject in each group was excluded due to intubation lasting fewer than 48 hours. Seven subjects were reintubated once (3 treatment vs 2 control), while one subject per group was reintubated twice. Six ETTs were accidentally discarded at extubation (4 treatment vs 2 control), giving a total of 37 and 40 tubes collected in the cleaning and control groups, respectively (Fig. 3).

Baseline characteristics of the study population are shown in Table 1. No significant differences between the 2 study groups were recorded at baseline. Specifics of the different ETTs collected throughout the study are provided in the supplementary materials at http://www.rcjournal.com.
Table 1. Study Population and Baseline Characteristics

\begin{tabular}{|c|c|c|}
\hline & $\begin{array}{l}\text { Control Group } \\
\text { (36 Subjects)* }\end{array}$ & $\begin{array}{l}\text { Treatment Group } \\
(36 \text { Subjects)* }\end{array}$ \\
\hline Sex, female, $n(\%)$ & $16(44)$ & $14(39)$ \\
\hline Age, $y$, mean $\pm S D$ & $64 \pm 17$ & $59 \pm 19$ \\
\hline $\mathrm{BMI}, \mathrm{kg} / \mathrm{m}^{2}$, mean $\pm \mathrm{SD}$ & $29.2 \pm 7.2$ & $28.3 \pm 5.1$ \\
\hline SAPS II, mean \pm SD & $46 \pm 13$ & $46 \pm 12$ \\
\hline $\mathrm{APACHE}$ II, mean $\pm \mathrm{SD}$ & $22 \pm 7$ & $22 \pm 7$ \\
\hline $\begin{array}{l}\text { Days mechanical ventilation, } \\
\text { mean } \pm \mathrm{SD}\end{array}$ & $7.1 \pm 3.6$ & $7.0 \pm 4.5$ \\
\hline Days ICU stay, mean $\pm \mathrm{SD}$ & $12.1 \pm 7.9$ & $12.2 \pm 8.0$ \\
\hline \multicolumn{3}{|l|}{$\begin{array}{l}\text { Reason for mechanical } \\
\text { ventilation, } n(\%)\end{array}$} \\
\hline Respiratory failure & $14(39)$ & $6(17)$ \\
\hline Cardiovascular failure & $6(17)$ & $7(19)$ \\
\hline CNS disorders & $7(20)$ & $9(25)$ \\
\hline Septic shock & $7(19)$ & $8(22)$ \\
\hline Trauma & $1(3)$ & $5(14)$ \\
\hline Other & $1(3)$ & $1(3)$ \\
\hline \multicolumn{3}{|l|}{ Vital signs, mean $\pm \mathrm{SD}$} \\
\hline $\mathrm{HR}$, beats/min & $84 \pm 23$ & $90 \pm 20$ \\
\hline Blood pressure, $\mathrm{mm} \mathrm{Hg}$ & $76 \pm 11$ & $77 \pm 12$ \\
\hline $\mathrm{S}_{\mathrm{pO}_{2}}$ of population & $97 \pm 3$ & $98 \pm 2$ \\
\hline \multicolumn{3}{|l|}{ Ventilatory settings, mean \pm SD } \\
\hline $\mathrm{V}_{\mathrm{T}}, \mathrm{mL} / \mathrm{kg} \mathrm{BW}$ & $5.4 \pm 1.4$ & $5.7 \pm 1.4$ \\
\hline Frequency, breaths/min & $22 \pm 6$ & $21 \pm 7$ \\
\hline $\mathrm{PEEP}, \mathrm{cm} \mathrm{H} \mathrm{H}_{2} \mathrm{O}$ & $8 \pm 4$ & $8 \pm 3$ \\
\hline $\mathrm{F}_{\mathrm{IO}_{2}}$ & $0.47 \pm 0.19$ & $0.53 \pm 0.20$ \\
\hline $\begin{array}{l}\text { * One subject excluded in each group d } \\
\text { BMI = body mass index } \\
\text { SAPS = Simplified Acute Physiology } \mathrm{S} \\
\text { APACHE = Acute Physiology and Chr } \\
\text { CNS = central nervous system } \\
\text { HR = heart rate } \\
V_{\mathrm{T}}=\text { tidal volume } \\
\text { BW = body weight }\end{array}$ & $\begin{array}{l}\text { tubation lasting fewer } \\
\text { alth Evaluation }\end{array}$ & han $48 \mathrm{~h}$ \\
\hline
\end{tabular}

\section{High-resolution Computed Tomography (Table 2)}

Endotracheal tubes cleaned with the endOclear device every 8 hours as a supplement to the standard of care showed reduced mucus accumulation (Mucus Volume: $0.56 \pm 0.12 \mathrm{~mL}$ vs $0.71 \pm 0.28 \mathrm{~mL}$, treatment vs control, $P=.004)$. A significant difference was also recorded after normalization of mucus for the total luminal volume (overall occlusion: $6.3 \pm 1.7 \%$ vs $8.9 \pm 7.6 \%, P=.039$; Fig. 4 ). The HRCT slice of each tube showing the narrowest lumen exhibited significantly less occlusion in tubes treated with the device (maximum occlusion: $10.6 \pm 8.0 \%$ vs $17.7 \pm 13.4 \%, P=.007)$. ETTs from both groups showed variable degrees of ID reduction compared with their nominal size. In the most numerous subgroup of size $7.5 \mathrm{~mm}$ ETTs, the minimum ID was significantly wider in the cleaning group $(7.2[7.0-7.3] \mathrm{mm}$ vs $7.0[6.5-7.1] \mathrm{mm}$, $P=.001)$. No differences were recorded for 7.0 and $8.0 \mathrm{~mm}$ 
Table 2. HRCT Data

\begin{tabular}{|c|c|c|c|c|}
\hline No. of ETTs per group & Mucus Volume (mL) & Overall Occlusion (\%) & Max Occlusion (\%) & Minimum ID (mm) \\
\hline Control $(\text { no. }=39)^{*}$ & $0.71 \pm 0.28$ & $8.9 \pm 7.6$ & $17.7 \pm 13.4$ & $6.9(6.4-7.1)$ \\
\hline Treatment $($ no. $=37)$ & $0.56 \pm 0.12$ & $6.3 \pm 1.7$ & $10.6 \pm 8.0$ & $7.1(6.7-7.3)$ \\
\hline$P$ & .004 & .04 & .007 & .05 \\
\hline \multicolumn{5}{|c|}{$\begin{array}{l}\text { * Size } 6.5 \mathrm{~mm} \text { tube collected from a subject in the control group excluded from high-resolution computed tomography analysis } \\
\text { ETT = endotracheal tube } \\
\text { ID = internal diameter }\end{array}$} \\
\hline
\end{tabular}

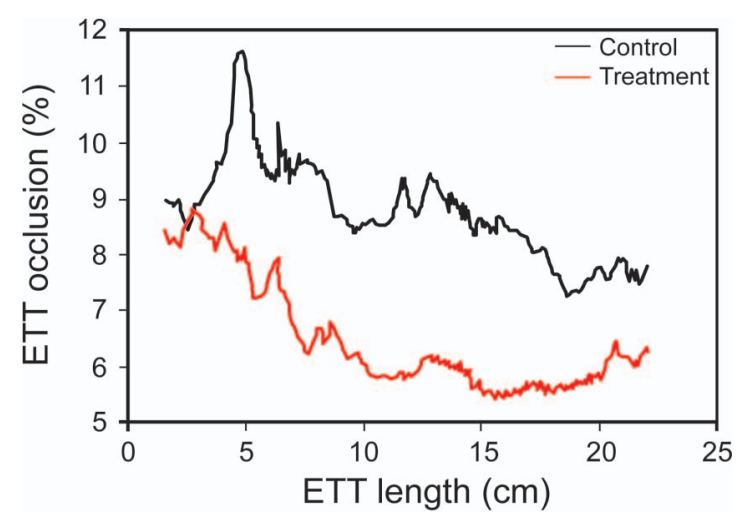

Fig. 4. Slice-by-slice mean luminal occlusion due to mucus accumulation along scanned endotracheal tubes (ETT) from lung $(0 \mathrm{~cm})$ to oral $(22 \mathrm{~cm})$ end. Data from 0 to $1.6 \mathrm{~cm}$ are intentionally omitted as described in the Methods section.

tubes. The ratio of ETT occlusion did not correlate with the length of intubation, as shown in the supplementary materials at http://www.rcjournal.com. A single $6.5 \mathrm{~mm}$ tube (control group) was excluded from HRCT analysis due to size discrepancy.

\section{Microbiology (Table 3)}

The isolation frequency of pathogenic bacteria in mucus retrieved from collected ETTs did not differ between the 2 groups. No difference was recorded in terms of antibiotic susceptibility patterns. Notably, the use of the device was associated with a 6-fold increase in the probability of finding ETTs for which no bacteria at all were isolated. Also, known VAP-causative gram-negative organisms (GN) were $50 \%$ less likely to be found in cleaned ETTs than in controls. However, these trends did not reach statistical significance (Relative Risk [95\% CI], No growth: 6.49 [0.81-51.36], $P=.07$; gram-negative VAP-causatives: $0.50[0.23-1.1], P=.08)$.

\section{Vital Signs and Respiratory Parameters}

Data collected 3 times daily at the bedside were grouped into 4 main time-points (study d-1, d-3, d-5, and d-7). Further details about recorded ventilatory settings and the effect of
Table 3. Colonization of Collected ETTs by Bacterial and Candida Species

\begin{tabular}{lcrll}
\hline \hline & $\begin{array}{c}\text { Control } \\
\text { no. ETTs } \\
(\%)\end{array}$ & $\begin{array}{c}\text { Treatment } \\
\text { no. ETTs } \\
(\%)\end{array}$ & $\begin{array}{c}\text { Frequency, } \\
\text { breaths/min } \\
(95 \% \text { CI })\end{array}$ & $P$ \\
\hline No growth & $1(3)$ & $6(16)$ & $6.49(0.81-51.36)$ & .07 \\
Pathogens* $^{*}$ VAP causatives $^{\dagger}$ & $21(53)$ & $14(38)$ & $0.72(0.43-1.2)$ & .2 \\
MDR & $15(38)$ & $7(19)$ & $0.50(0.23-1.1)$ & .08 \\
Candida spp. & $10(25)$ & $8(22)$ & $0.86(0.38-1.95)$ & .72 \\
& $21(53)$ & $16(43)$ & $0.82(0.51-1.32)$ & .4
\end{tabular}

* Staphylococcus aureus, Klebsiella spp, Haemophilus spp, Stenotrophomonas maltophilia, Enterobacter spp, Pseudomonas aeruginosa, Escherichia coli, Acinetobacter spp, and other isolates.

VAP causatives $=$ Klebsiella spp, Enterobacter spp, Pseudomonas spp, E. coli, Haemophilus spp, Acinetobacter spp, Stenotrophomonas maltophilia ${ }^{15}$.

MDR = multi-drug resistant, defined as acquired nonsusceptibility to at least 1 agent in 3 or more antimicrobial categories

cleaning on ventilatory parameters can be found in the supplementary materials at http://www.rcjournal.com.

\section{Safety and Staff Feedback}

In-hospital follow-up was completed for all subjects. No adverse events occurred throughout a total of 584 cleaning procedures. Completed questionnaires from a total $28 \mathrm{RRTs}$ were collected: $25 / 28$ users $(82 \%)$ considered the endOclear to be "much better" (grade 4) or "better" (grade 3) than standard suctioning. Ease of setup was also positively evaluated, and the device's overall assigned score was $7.1 \pm 2.1$. Please refer to the supplementary materials at http://www.rcjournal.com for a detailed description of follow-up data and a full report of the user survey.

\section{Discussion}

This randomized, controlled clinical trial evaluated the efficacy of a device specifically designed to clean the endotracheal tube lumen of airway secretions. We showed that tubes treated with the endOclear were significantly less occluded than controls, as measured by HRCT.

Narrowing of the endotracheal tube due to secretions is usually an underestimated problem. ${ }^{17}$ Mucus attached to 
the inner ETT surface reduces the volume available to air flow, ${ }^{5}$ thereby leading to increased airway resistance ${ }^{18}$ and patient's work of breathing (WOB) ${ }^{4}$ In some cases, the gradual luminal narrowing can progress to complete occlusion of the ETT. In prior studies, ${ }^{19,20}$ the degree of ETT occlusion was estimated by using acoustic reflectometry and averaged between $10 \%$ and $15 \%$. This noninvasive technique indirectly estimates the tube cross-sectional area (CSA), by analysis of sound waves as they propagate throughout the tube. Our group developed and reported on an innovative methodology for the analysis of ETT occlusion based on HRCT imaging. ${ }^{21}$ We detected an average $25 \%$ CSA reduction, compared with paired control unused tubes. Imaging data correlated with in vitro measurements of resistance. Moreover, a variable degree of mucus partially occluding the ETT could also be visualized on standard chest CT scans. ${ }^{3}$ Compared with acoustic reflectometry, our novel assay based on HRCT offers several advantages, including: (1) the direct visualization and quantitation of mucus volume, and (2) a precise definition of the mucus accumulation pattern across the whole ETT length.

Currently, blind suctioning through a small flexible catheter is the most common method to remove secretions from within the ETT. ${ }^{22}$ This maneuver can injure the tracheal mucosa, ${ }^{23}$ decrease lung volume leading to hypoxia, ${ }^{24}$ trigger cardiac arrhythmias, ${ }^{25}$ and increase intracranial pressure. ${ }^{26}$ In addition, the use of blind suctioning has also been associated with further impairment of tracheal mucociliary clearance function ${ }^{27}$ together with dislodging emboli of pathogens from the ETT biofilm to the lower airway. ${ }^{28}$ Several novel dedicated medical devices have been developed for the specific purpose of ETT cleaning. Different from suctioning, the aim of these devices is to remove mucus by physically scraping the inner wall of the tube. Among this new generation of cleaning catheters, we found the endOclear to be a safe and effective device in the clinical setting. ${ }^{13}$ Its efficacy, however, had never been tested in a randomized, controlled fashion.

According to our HRCT results, the use of the endOclear device led to a reduced amount of mucus attached to the inner wall of the ETT after extubation. Consequently, tubes in the treatment group had reduced occlusion. Wright et al demonstrated that the ETT alone significantly contributes to total air flow resistance. ${ }^{29}$ Luminal narrowing due to mucus accumulation further increases resistance, which varies inversely to the fourth power of the tube's radius, according to the Poiseulle equation:

$$
\Delta \mathrm{P}=8 \mu L Q \times\left(\pi r^{4}\right)^{-1}
$$

where $\Delta \mathrm{P}$ is the pressure drop, $L$ is the length of the conduit, $\mu$ is the fluid viscosity, $Q$ is the flow, and $r$ is the radius. An increased air flow resistance due to luminal narrowing significantly adds to subjects' WOB, as shown in vivo by Heyer et al. ${ }^{30}$ According to the authors' estimate, a $10 \%$ reduction in the ETT cross-sectional area would correspond to a $27 \%$ increase in a patient's WOB. ${ }^{30}$ Subjects receiving pressure-support ventilation, especially if awake and/or during weaning protocols, might considerably benefit from the reduced respiratory load otherwise imposed by accumulated secretions.

Conti et $\mathrm{al}^{31}$ tested an "obstruction remover" in 8 mechanically ventilated subjects, showing a significant reduction of in vivo airway resistance, as well as a reduced WOB. In 2003, the Mucus Shaver was developed by Kolobow et al. ${ }^{32}$ This device, although not commercially available, was shown to be effective in clearing secretions from the ETT first in an animal study, ${ }^{32}$ followed by a small clinical trial. ${ }^{33}$ More recently, Liu et al ${ }^{34}$ investigated the use of $8 \mathrm{~F}$ sterile urinary catheters as an easily available alternative to the Shaver in a population of 45 intubated children. Similar to the Shaver, the regular implementation of this ETT cleaning maneuver reduced bacterial colonization and biofilm thickness as determined by confocal microscopy. However, none of these devices are commercially available, and all of these studies lacked accurate measurements of ETT patency.

In our study, we also tested the hypothesis that, by mechanically scraping the ETT inner surface, the use of the endOclear could interfere with the process of biofilm formation, therefore delaying colonization by clinically relevant pathogens. To test this secondary end point, we categorized bacterial isolates as "VAP causatives," according to a retrospective analysis of VAP microbial etiology conducted at our institution. ${ }^{15}$ In this work by Arvanitis et al, 208 VAP cases over a 5-y period were identified by searching a large hospital infection control database (approximately $40 \mathrm{VAP}$ cases/year). Nevertheless, we did not find any significant difference in the rate of ETT colonization between the 2 groups. Among our selected population of intubated subjects, we registered a total of only 7 clinically diagnosed VAP cases over 6 months. Focusing on the ETT microbial colonization by Gram-negative VAPcausative agents, we isolated such bacteria in 7 treated ETTs versus 15 controls, meaning a 50\% relative reduction in the risk of isolating such pathogens in cleaned tubes. However, it is likely that this trend did not reach statistical significance due to the small sample size. Alternatively, the use of a cleaning device might not be effective by itself in limiting the process of biofilm formation. We are currently exploring whether there is a synergic effect between ETT cleaning with the endOclear and the use of an antibacterial coating on the ETT lumen to reduce biofilm formation in the ETT (ClinicalTrials.gov NCT\#02120001). 
Throughout our study enrollment, the endOclear was safely used, with no adverse events reported over several ETT cleaning maneuvers. However, albeit unlikely, ETT displacement and tracheal injury must still be considered as potential risks associated with the use of the device. We believe the careful application of the available safety measures (red toggle, centimeter markings, blue safety stop) will significantly reduce the likelihood of such complications.

This study has several limitations. First, the enrollment design did not control ETT size. Ideally, to avoid any confounding factors, enrolled subjects should have been intubated with same-sized, same-brand tubes, or at least a size-balanced randomization should have been implemented. Second, in a trial involving 5 heterogeneous ICUs, no unit-based randomization was planned to limit possible confounders related to the type of admission. However, despite a slight imbalance in subjects being intubated due to respiratory failure, no significant baseline differences were recorded between the 2 groups. Third, no blinding of the respiratory therapists performing the study treatment could physically be applied, potentially leading to a bias due to the staff being more scrupulous when using the new device compared with usual care. Fourth, our study protocol did not include any restrictions on the institutional practice for tracheal suctioning. The aim of the study was to test the efficacy of routine ETT cleaning with a dedicated device in addition to the standard of care. However, a different rate of suctioning between the groups, although unlikely, could have altered our findings. Finally, this is a phase 2 randomized clinical trial to establish the effectiveness of cleaning of the lumen of the ETT; therefore, no conclusions can be drawn regarding major clinical outcomes.

Larger studies are needed in order to establish the role of ETT cleaning in terms of reducing time on the ventilator, length of ICU stay, and VAP incidence. Additionally, technical features must be developed and tested to improve the functionality of cleaning devices and promote their routine use. At our institution, the use of the endOclear was adequately implemented with no adverse events reported, and the respiratory therapists involved in the protocol positively reviewed the device. The endOclear is a first-generation product that still requires disconnection of the patient from the mechanical ventilator. A promising solution would be to implement such cleaning apparatus on a closed suction system, to avoid repeated disruptions of the breathing circuit.

\section{Conclusions}

In our trial, ETT luminal narrowing was safely and effectively reduced by the implementation of a routine cleaning protocol, which included the use of a dedicated device. The subsequently increased tube patency might be beneficial to critically ill mechanically ventilated patients. Larger studies are needed to test whether this translates to improved clinical outcomes.

\section{ACKNOWLEDGMENTS}

Eleftherios Mylonakis MD PhD (Rhode Island Hospital and The Miriam Hospital, Warren Alpert Medical School of Brown University, Providence, Rhode Island) for his help in the study design and review of microbiological data.

Francesco Nordio PhD (Brigham and Women's Hospital, Boston, Massachusetts) for statistical consultation and review.

Medical student Dominique Monlezun for his assistance in the processing of study samples and data collection.

Mary Delaney, Andrea Dubois, Rose Deng, and Qing Liu (Center for Clinical and Translational Metagenomics, Brigham \& Women's Hospital, Boston, Massachusetts) for microbiological samples processing.

Jessica Truelove, BS, Benoit Tricot, MS, and the Center for System Biology-Mouse Imaging Program at the Massachusetts General Hospital (Boston, Massachusetts) for their help with HRCT scanning and imaging analysis.

The Nursing and Respiratory Therapy staff of the Massachusetts General Hospital-Critical Care Center (Boston, Massachusetts).

\section{REFERENCES}

1. Trawöger R, Kolobow T, Cereda M, Giacomini M, Usuki J, Horiba K, Ferrans VJ. Clearance of mucus from endotracheal tubes during intratracheal pulmonary ventilation. Anesthesiology 1997;86(6): 1367-1374.

2. Knowles MR, Boucher RC. Mucus clearance as a primary innate defense mechanism for mammalian airways. J Clin Invest 2002; 109(5):571-577.

3. Mietto C, Pinciroli R, Piriyapatsom A, Thomas JG, Bry L, Delaney $\mathrm{ML}$, et al. Tracheal tube obstruction in mechanically ventilated patients assessed by high-resolution computed tomography. Anesthesiology 2014;121(6):1226-1235.

4. Shapiro M, Wilson RK, Casar G, Bloom K, Teague RB. Work of breathing through different sized endotracheal tubes. Crit Care Med 1986;14(12):1028-1031.

5. Bock KR, Silver P, Rom M, Sagy M. Reduction in tracheal lumen due to endotracheal intubation and its calculated clinical significance. Chest 2000;118(2):468-472.

6. Inglis TJ. Evidence for dynamic phenomena in residual tracheal tube biofilm. Br J Anaesth 1993;70(1):22-24.

7. Gil-Perotin S, Ramirez P, Marti V, Sahuquillo JM, Gonzalez E, Calleja I, et al. Implications of endotracheal tube biofilm in ventilator-associated pneumonia response: a state of concept. Crit Care 2012;16(3):R93.

8. Singh PK, Parsek MR, Greenberg EP, Welsh MJ. A component of innate immunity prevents bacterial biofilm development. Nature 2002; 417(6888):552-555.

9. Stewart PS, Costerton JW. Antibiotic resistance of bacteria in biofilms. Lancet 2001;358(9276):135-138.

10. Shah S, Fung K, Brim S, Rubin BK. An in vitro evaluation of the effectiveness of endotracheal suction catheters. Chest 2005;128(5): 3699-3704.

11. Van de Leur JP, Zwaveling JH, Loef BG, Van der Schans CP. Endotracheal suctioning versus minimally invasive airway suctioning in intubated patients: a prospective randomised controlled trial. Intensive Care Med 2003;29(3):426-432.

12. Pinciroli R, Mietto C, Berra L. Respiratory therapy device modifications to prevent ventilator-associated pneumonia. Curr Opin Infect Dis 2013;26(2):175-183. 


\section{ETT SECRETION REMOVAL}

13. Mietto C, Foley K, Salerno L, Oleksak J, Pinciroli R, Goverman J, Berra L. Removal of endotracheal tube obstruction with a secretion clearance device. Respir Care 2014;59(9):e122-e126.

14. Chastre J, Fagon JY. Ventilator-associated pneumonia. Am J Respir Crit Care Med 2002;165(7):867-903.

15. Arvanitis M, Anagnostou T, Kourkoumpetis TK, Ziakas PD, Desalermos A, Mylonakis E. The impact of antimicrobial resistance and aging in VAP outcomes: experience from a large tertiary care center. PLoS ONE 2014;9(2):e89984.

16. Magiorakos AP, Srinivasan A, Carey RB, Carmeli Y, Falagas ME, Giske CG, et al. Multidrug-resistant, extensively drug-resistant and pandrug-resistant bacteria: an international expert proposal for interim standard definitions for acquired resistance. Clin Microbiol Infect 2012;18(3):268-281.

17. Boqué MC, Gualis B, Sandiumenge A, Rello J. Endotracheal tube intraluminal diameter narrowing after mechanical ventilation: use of acoustic reflectometry. Intensive Care Med 2004;30(12):2204-2209.

18. Lofaso F, Louis B, Brochard L, Harf A, Isabey D. Use of the Blasius resistance formula to estimate the effective diameter of endotracheal tubes. Am Rev Respir Dis 1992;146(4):974-979.

19. Van Surell C, Louis B, Lofaso F, Beydon L, Brochard L, Harf A, et al. Acoustic method to estimate the longitudinal area profile of endotracheal tubes. Am J Respir Crit Care Med 1994;149(1):28-33.

20. Shah C, Kollef MH. Endotracheal tube intraluminal volume loss among mechanically ventilated patients. Crit Care Med 2004;32(1):120-125.

21. Pinciroli R, Mietto C, Berra L. Use of high-definition computed tomography to assess endotracheal tube luminal narrowing after mechanical ventilation. Anesthesiology 2013;119(1):202.

22. American Association for Respiratory Care. AARC Clinical Practice Guidelines. Endotracheal suctioning of mechanically ventilated patients with artificial airways 2010. Respir Care 2010;55(6):758-764.

23. Sackner MA. Pathogenesis and prevention of tracheobronchial damage with suction procedures. Chest 1973;64(3):284.

24. Guglielminotti J. Effects of tracheal suctioning on respiratory resistances in mechanically ventilated patients. Chest 1998;113(5):1335.
25. Stone KS, Talaganis SA, Preusser B, Gonyon DS. Effect of lung hyperinflation and endotracheal suctioning on heart rate and rhythm in patients after coronary artery bypass graft surgery. Heart Lung 1991;20(5 Pt 1):443-450.

26. Brucia J, Rudy E. The effect of suction catheter insertion and tracheal stimulation in adults with severe brain injury. Heart Lung 1996;25(4):295-303.

27. Landa JF, Kwoka MA, Chapman GA, Brito M, Sackner MA. Effects of suctioning on mucociliary transport. Chest 1980;77(2): 202-207.

28. Inglis TJ, Millar MR, Jones JG, Robinson DA. Tracheal tube biofilm as a source of bacterial colonization of the lung. J Clin Microbiol 1989;27(9):2014-2018.

29. Wright PE, Marini JJ, Bernard GR. In vitro versus in vivo comparison of endotracheal tube airflow resistance. Am Rev Respir Dis 1989;140(1):10-16.

30. Heyer L, Louis B, Isabey D, Lofaso F, Brochard L, Fredberg JJ, Harf A. Noninvasive estimate of work of breathing due to the endotracheal tube. Anesthesiology 1996;85(6):1324-1333.

31. Conti G, Rocco M, De Blasi RA, Lappa A, Antonelli M, Bufi M, Gasparetto A. A new device to remove obstruction from endotracheal tubes during mechanical ventilation in critically ill patients. Intensive Care Med 1994;20(8):573-576.

32. Kolobow T, Berra L, Li Bassi G, Curto F. Novel system for complete removal of secretions within the endotracheal tube: the Mucus Shaver. Anesthesiology 2005;102(5):1063-1065.

33. Berra L, Coppadoro A, Bittner EA, Kolobow T, Laquerriere P, Pohlmann JR, et al. A clinical assessment of the Mucus Shaver: a device to keep the endotracheal tube free from secretions. Crit Care Med 2012;40(1):119-124.

34. Liu W, Zuo Z, Ma R, Zhang X. Effect of mechanical cleaning of endotracheal tubes with sterile urethral catheters to reduce biofilm formation in ventilator patients. Pediatr Crit Care Med 2013;14(7):e338-e343.

This article is approved for Continuing Respiratory Care Education credit. For information and to obtain your CRCE

(free to AARC members) visit www.rcjournal.com

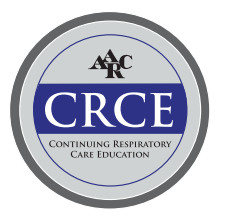

